Acta vet. scand. 1990, 31, 125-127.

Brief Communication

\title{
The Effect of Fractionated Weaning on Reproductive Performance in Primiparous Sows on a Commercial Farm
}

A delay in the interval from weaning to oestrus is a common problem in the pig industry and is more pronounced in primiparous than in multiparous sows. In Sweden, only about $60 \%$ of first-litter sows come into oestrus within 7 days of weaning, whereas the corresponding figure for multiparous sows is $>80 \%$. Similarly, an investigation in Thailand showed that about $60 \%$ and $<80 \%$ of the primiparous sows studied came into oestrus within 10 and 21 days of weaning, respectively.

Recent studies in pigs have demonstrated that lactational oestrus or shorter weaningto-oestrous intervals can be induced by altering or disrupting nursing patterns. By weaning some of the heaviest piglets several days earlier (fractionated weaning), the interval from weaning to oestrus can be shortened to various extents (Cox et al. 1983, Kunavongkrit et al. 1985, Riley et al. 1985, Rojkittikhun et al. 1990). Knowledge regarding the influence of fractionated weaning on reproductive performance in primiparous sows and its practical application in commercial farms, especially in tropical countries, is very limited, however.

The trial described here was conducted for 11/2 years (May 1988 - Oct 1989) on a 1,000sow commercial pig farm in Thailand. On this farm, the sows were kept in confinement in open buildings (both mating and farrowing houses). Cooling systems including water dripping and sprinkling were used regularly throughout the year. The average monthly temperature during the experimental period in the district where the farm was located was $27.1 \pm 2.2^{\circ} \mathrm{C}$. Feed for the lactating sows, provided ad libitum, contained $14 \%$ crude protein and $13.2 \mathrm{MJ}$ of metabolisable energy per $\mathrm{kg}$.

From 138 primiparous crossbred (Large white $\times$ Landrace) sows, 69 pairs were formed. Farrowing dates for sows within a pair did not differ by more than 1 week, and their litter sizes did not differ by more than 2 piglets, with a minimum of 7 piglets remaining at 4 weeks. The number of piglets nursing each sow was adjusted to uniform size within $24-48 \mathrm{~h}$ after birth. One sow from each pair was randomly assigned to treatment (F), which consisted of weaning the heaviest half of the litter during the fourth week of lactation and the remainder 3 days later. To follow the routine weaning programme of the farm, the first weaning was done on a Friday and the final weaning on the following Monday (at the average $27.4 \pm 1.5$ and $30.5 \pm 1.5$ days of lactation for the first and final weaning, respectively). Control sows (C) were routinely weaned during the fourth and fifth week of lactation (at the average $30.5 \pm 1.6$ days of lactation). Oestrous detection was performed twice daily after the first weaning in farrowing pens and after the final weaning in a mating house in the presence of a boar. The sows were bred naturally with different boars at least twice within the duration of the standing oestrus. Hormonal therapy (using PG 
Table 1. Frequency distribution of weaning-to-mating intervals in the sows subjected to fractionated weaning and conventional weaning.

\begin{tabular}{l|r|r|r|r}
\hline WMI $^{\prime}$ & \multicolumn{2}{|c|}{ No. of sows } & \multicolumn{2}{c}{ Cumulative percentages } \\
(day) & \multicolumn{1}{|c|}{$\mathrm{C}^{2}$} & \multicolumn{1}{c}{$\mathrm{F}^{3}$} & $\mathrm{C}$ & \multicolumn{1}{c}{$\mathrm{F}$} \\
\hline 3 & - & 2 & - & 2.9 \\
4 & 8 & 11 & 11.6 & 18.8 \\
5 & 32 & 30 & 58.0 & 62.3 \\
6 & 8 & 7 & 69.6 & 72.5 \\
7 & 3 & 8 & 73.9 & 84.1 \\
$8-13$ & 9 & 2 & 87.0 & 87.0 \\
$\geq 14$ & 9 & 9 & 100.0 & 100.0 \\
\hline
\end{tabular}

1)weaning-to-mating interval ${ }^{2)}$ Control group

3)Treatment group (fractionated weaning)

Table 2. Effect of fractionated weaning on the reproductive performance of the sows.

\begin{tabular}{lcrl}
\hline & \multicolumn{2}{c}{ Group } & \multirow{2}{*}{ Significance } \\
\cline { 2 - 3 } & \multicolumn{1}{c}{ C } & \multicolumn{1}{c}{$\mathrm{F}$} & \\
\hline No. of sows & 69 & 69 & \\
No. of weaned & & & \\
piglets & $10.1 \pm 1.0$ & $10.0 \pm 0.5$ & \\
$\cdot .2$ WMI (day) & $6.7 \pm 0.4$ & $6.4 \pm 0.4$ & NS \\
$.3 \mathrm{P} 2$ & $11.1 \pm 0.4$ & $10.1 \pm 0.4$ & NS \\
\hline
\end{tabular}

'LSmean \pm SE

${ }^{1)} \mathrm{C}=$ control gr., $\mathrm{F}=$ treatment gr. (fractionated weaning)

2)Weaning-to-mating interval

${ }^{3)}$ No. of piglets born (dead + alive) in the second parity (No. of sows studied $=52$ pairs).

$600^{\mathrm{R}}$ ) was used routinely in sows which had not exhibited oestrus within 14 days of final weaning. Weaning-to-mating intervals (WMI) of $\geq 14$ days were recorded as 14 days for statistical evaluation. The number of piglets born (dead + alive) in the second parity (P2) were evaluated from only 52 pairs of sows as the pairs with incomplete data were excluded.

Data were analysed by least-square analysis of variance using the General Linear Model procedure (SAS Institute Inc. 1985). The statistical model used for analysing the diffe- rences within pairs of sows in WMI and in P2 included the following effects: treatment ( 2 levels), mating period ( 2 periods; Feb-Jul and Aug-Jan) and pair within mating period (69 pairs for WMI and 52 pairs for $\mathrm{P} 2$ ). Effects of fractionated weaning on the reproductive performance of the sows are presented in Tables 1 and 2. Lactational oestrus was not observed in any sow. Cumulative percentages of the sows coming into oestrus within 7 days of final weaning were 73.9 and $84.1 \%$ in the $C$ and $F$ sows, respectively. However, the mean intervals from weaning to mating were not significantly different between the 2 groups. P2, based on 52 pairs of sows, was not significantly different between the $C$ sows and the $F$ sows.

The present study demonstrated that fractionated weaning technique, as performed in this experiment, increased the percentage of primiparous sows bred within 7 days of weaning. However, for sows not having exhibited oestrus within 14 days of weaning, this technique seems to have had no benefit. Some of the post-weaning anoestrous sows may need another type of stimulation to induce oestrus, such as transportation/relocation or hormonal treatment. The fact that the numbers of piglets born in the second parity were similar in both groups of sows can be taken as evidence that ovulation occurred normally after fractionated weaning.

We conclude that the technique described here is a practical one that can increase the percentage of primiparous sows bred within 7 days of weaning.

\section{Acknowledgements}

This work was supported by grants from the Swedish Council for Forestry and Agricultural Research.

T. Rojkittikhun', S. Rojanasthien ', S. Einarsson ', N. Lundeheim ${ }^{3}$ and A. Rojkittikhun ${ }^{4}$ 
' Department of Obstetrics and Gynaecology, Faculty of Veterinary Medicine, ${ }^{3}$ Department of Animal Breeding and Genetics, Faculty of Agriculture, Swedish University of Agricultural Sciences, Uppsala, Sweden.

${ }^{2}$ Department of Obstetrics, Gynaecology and Animal Reproduction, Faculty of Veterinary Medicine, Kasetsart University, Thailand.

'E-sarnkarnkaset Co. Ltd., Nakornratchasima, Thailand.

\section{References}

Cox NM, Britt JH, Armstrong WD, Alhusen HD: Effect of feeding fat and altering weaning schedule on rebreeding in primiparous sows. J. Anim. Sci. 1983, 56, 21-29.
Kunavongkrit A, Rojanasthien S, Ogle RB: Effect of fractionated weaning on hormonal patterns and weaning to oestrus interval in sows. Swedish J. agric. Res. 1985, 15, 39-44.

Riley JE, Edwards SA, Simmins PH, Shepherd CM, Brade MA: The effects of fractionated weaning on sow productivity. Proc. $2^{\text {nd }}$ Int. Conf. Pig. Reprod. 1985, Columbia, U.S.A. (Abstract).

Rojkittikhun T, Rojanasthien S, Einarsson S, Madej $A$, Lundeheim N: Effect of fractionated weaning on hormonal patterns and weaning to oestrous interval in primiparous sows. Acta vet. scand. (accepted for publication).

SAS Institute Inc.: SAS User's Guide. SAS Institute Inc., Cary, N.C. 1985.

(Received February 6, 1990; accepted March 19, 1990).

Reprints may be requested from: Titima Rojkittikhun, Department of Obstetrics and Gynaecology, Faculty of Veterinary Medicine, Swedish University of Agricultural Sciences, S-750 07 Uppsàla, Sweden. 